\title{
Residual central nervous system damage due to organoarsenic poisoning
}

Kiyotaka Nakamagoe ${ }^{a}$, M.D., Ph.D.; Natsu Fujizuka ; Tadachika Koganezawa ${ }^{\text {b }}$ Ph.D.; Kotone Shimizu ${ }^{\text {a }}$;

Shino Takiguchi ${ }^{\text {a }}$ Takahiro Horaguchic ${ }^{\mathrm{c}}$ Ph.D.; Kazuhiro Ishii ${ }^{\mathrm{a}}$, M.D., Ph.D.; and Akira Tamaoka ${ }^{\mathrm{a}}$, M.D.,

Ph.D.

aDepartment of Neurology, Institute of Clinical Medicine, University of Tsukuba, Tsukuba, Ibaraki, Japan

${ }^{b}$ Department of Cardiovascular Physiology, Division of Biomedical Science, Faculty of Medicine,

University of Tsukuba, Tsukuba, Ibaraki, Japan

'Department of Physical Therapy, Faculty of Health Sciences, Gumma PAZ College, Takasaki, Gumma, Japan

Corresponding author: Kiyotaka Nakamagoe (K.N.)

Tel. \& Fax: +81-29-853-3224

E-mail: Nakamagoek@md.tsukuba.ac.jp

Running title: Organoarsenic-induced ocular movement disorders

Key words: biomarker; eye movement; organic arsenic; diphenylarsinic acid; toxicology; central nervous 
system; upbeat nystagmus; gaze-evoked nystagmus; square-wave jerks 


\section{ABSTRACT}

Background: Drinking well water contaminated with the organoarsenic compound diphenylarsinic acid (DPAA) causes central nervous system (CNS) disorders that improve within several years after last drinking such water. Subjective symptoms such as lightheadedness and dizziness appear to persist, however, suggesting CNS damage. We evaluated CNS damage due to DPAA by detecting abnormal eye movements.

Methods: Subjects comprised 29 victims of exposure to DPAA in whom this substance had been detected in the nails. Investigations were performed more than 3 years following cessation of DPAA exposure. Abnormal eye movements were monitored using electronystagmography. We analysed unpaired t-test between exposure subjects who exhibited upbeat nystagmus and those who did not. Upbeat nystagmus parameters were measured, and mean values were calculated. Associations between the properties of upbeat nystagmus and maximum concentrations of DPAA among DPAA exposure were also investigated.

Results: Upbeat nystagmus was common among exposure victims, occurring in 23 of 29 subjects (79.0\%). The subjects with upbeat nystagmus had significantly higher ratio than those without upbeat nystagmus in the points of subjective symptoms and DPAA concentration of drinking water $(p<0.01)$. The slow-phase amplitude of upbeat nystagmus enlarged with increasing DPAA concentrations, showing a significant positive correlation $(p<0.05)$. These findings suggest that the level of exposure to DPAA affects the properties of nystagmus. High-frequency pathological SWJ were seen in 14 of 29 patients (48.0\%), and mean SWJ frequency was $112.4 \pm 16.7 / \mathrm{min}$.

Conclusions: Detection of abnormal ocular movements may be useful in evaluating residual/persistent/chronic CNS damage due to organoarsenic poisoning. 


\section{INTRODUCTION}

Pollution of potable well water with the organic arsenic compound diphenylarsinic acid (DPAA; chemical formula, $\mathrm{C}_{12} \mathrm{H}_{11} \mathrm{AsO}_{2}$ ) was discovered in Japan in 2003 (Ishii et al., 2004; Nakamagoe et al., 2006). Materials used in the manufacture of chemical weapons were subsequently found to have been abandoned in this area, and DPAA had leached into well water some 60 years after the end of the war (Ishii et al., 2007; Nakamagoe, 2012).

In 2003, DPAA poisoning was observed to cause central nervous system (CNS) disorders of higher function, dysarthria and cerebellar ataxia of the limbs and trunk, pyramidal signs, myoclonus, and tremors (Ishii et al., 2004; Nakamagoe et al., 2006). Abnormal eye movements contributing to dizziness and lightheadedness were also present. Damage to the cerebellum and brainstem is generally known to result in dizziness and lightheadedness, which are directly attributable to the abnormal eye movements (Leigh and Zee, 2006). DPAA poisoning was not associated with symptoms such as sensory disturbance or loss of deep tendon reflex (Ishii et al., 2004), and a nerve conduction study of the limbs showed no peripheral neuropathy (Nakamagoe, 2012). Moreover, short-latency somatosensory evoked potential testing and brainstem auditory evoked potential testing also exhibited changes, albeit minor, in response to brainstem damage without peripheral neuropathy and peripheral vestibular lesions (Nakamagoe, 2012). This clinical course is quite dissimilar to that of chronic inorganic arsenic poisoning, which is characterized by sensory-predominant polyneuropathy (Kawasaki et al., 2002).

The clinical course initially suggested that DPAA poisoning symptoms would prove reversible, and that CNS symptoms would improve after cessation of DPAA ingestion. When residents stopped drinking water from the contaminated wells, concentrations of DPAA fell rapidly, and soon became undetectable in biological samples from exposure victims. Indeed, most symptoms virtually disappeared within a few years.

However, exposure victims continued to complain of persistent dizziness and lightheadedness. Although other neurological abnormalities disappeared over time, symptoms due to abnormal eye movements remained. This course suggested either accumulation of DPAA somewhere in the body or long-term damage to the CNS.

Eye movement testing offers a non-invasive method of evaluating brain damage that is also comparatively simple and cheap. Compared with evoked potential testing, this method also makes it 
comparatively easy to assess CNS damage due to organoarsenic compounds.

We focused our study on upbeat nystagmus, a type of abnormal vertical eye movement, as a manifestation of residual CNS damage due to chronic organoarsenic poisoning.

\section{METHODS}

\subsection{Subjects}

Subjects comprised 29 victims of DPAA exposure residing in Kamisu City who had ingested well water from which DPAA had been detected and from whose nail samples DPAA had also been detected in 2003. The eye movement measurements in this study were performed in 2006-2011, by which time more than 3 years had passed since the cessation of DPAA exposure. All patients were thus considered to be in the chronic phase.

We also recruited volunteers living in Tsukuba as normal subjects and set up two control groups to account for any effects of age on abnormal eye movements: one group containing young normal subjects (in their teens or $20 \mathrm{~s}$ ); and the other containing elderly normal subjects ( $\geq 60$ years old). The same eye movement tests were applied in both groups. These tests were approved by a University of Tsukuba ethics committee. Normal subjects had their medical histories taken and underwent examination in advance to confirm the absence of neurological and otological abnormalities such as paralysis, sensory disturbance, ataxia, hypacusis, and gait disturbance. Consent was obtained from all subjects prior to participation.

\subsection{Ocular movement measurement}

Spontaneous eye movements were monitored using infrared eyeglasses (First, Tokyo, Japan). Electronystagmography was performed under bright-field and dark-field conditions using a direct current (DC) recording electronystagmograph (First). Eye movement data were analysed using a data acquisition and analysis system (PowerLab; AD Instruments, Castle Hill, Australia), with sampling and analysis performed at $1 \mathrm{kHz}$.

We defined the criteria used to designate the presence or absence of upbeat nystagmus: vertical nystagmus with rapid phase in the upward direction was estimated as upbeat nystagmus (Fig. 1) when we observed ocular movements in the central position in dark for 3 min under infrared eyeglasses or electronystagmography. 
Upbeat nystagmus was extracted from the eye movements measured, the various eye movement parameters (waveform frequency $[\mathrm{Hz}]$, slow-phase amplitude $\left[^{\circ}\right]$ and speed $[\% / \mathrm{s}$, and fast phase amplitude $\left[{ }^{\circ}\right]$ and speed $[\% / \mathrm{s}]$ ) were measured, and mean values for exposure victims were calculated.

Among the measured eye movements, square oscillations (Fig. 2) with a frequency $\geq 30 /$ min were detected as pathological square-wave jerks (SWJ) for 3 min under electronystagmography. Wave frequency (/min) was measured and mean values were calculated for each exposed individual.

\subsection{DPAA concentration}

High-speed liquid chromatography and inductively coupled plasma mass spectrometry were used to measure DPAA concentrations in contaminated well water and nail samples from exposure victims (Ishizaki et al., 2005; Kinoshita et al., 2008). This study used maximum DPAA concentrations from nail samples taken from exposure victims during 2003, as the period they were last exposed to DPAA.

\subsection{Statistical analysis}

SPSS Statistics base software (IBM, New York, NY, USA) was used for statistical investigation. We used unpaired t-tests to compare results (age, exposure length, interval to examination of eye movements, DPAA concentrations, and subjective symptoms) between exposure subjects exhibiting upbeat nystagmus $(n=23)$ and those not exhibiting upbeat nystagmus $(n=6)$. We also analysed associations between DPAA concentrations and properties of upbeat nystagmus in the 15 individuals (mean ( \pm standard deviation) age, $44.6 \pm 18.3$ years; 8 men, 7 women) for whom DPAA concentration in nails had been measured and in whom upbeat nystagmus was measured by electronystagmography. Pearson's correlation coefficients and $p$ values were calculated, and statistical significance was determined with the level of significance set at $5 \%$.

\section{RESULTS}

Table 1 shows the characteristics of individuals exposed to DPAA. Mean age was $44.0 \pm 15.3$ years, and the group comprised 15 men and 14 women. Mean age in the young control group was $22.5 \pm 0.2$ years, and the group comprised 16 men and 16 women. Mean $( \pm$ SD) age in the elderly control group was 
$70.6 \pm 0.4$ years, and the group comprised 16 men and 16 women. No significant differences in sex ratio were apparent between DPAA exposure victims and normal subject groups $(p>0.3)$.

The mean period during which individuals drank contaminated water was $1420 \pm 389$ days. Maximum DPAA concentration in the nails of exposure victims measured at the time of discovery was 7.9-7200 $\mathrm{ng} / \mathrm{g}$ (mean, $841 \pm 1763.6 \mathrm{ng} / \mathrm{g}$ ). During the chronic phase, when the present study was performed, DPAA concentration was below the detection threshold in the nails of all exposure victims. Subjective symptoms including non-rotational dizziness, lightheadedness, and shaking were evident in $38 \%$ of victims.

\section{1 Nystagmus}

Upbeat nystagmus was common, occurring in 23 of 29 exposed patients (79.3\%) (Fig 1). Upward gaze-evoked nystagmus was evident in 7 of 29 victims (24.1\%) and horizontal gaze-evoked nystagmus was also evident in 6 of 29 victims (20.7\%). Upbeat nystagmus was evident in 1 member each of the young and elderly control groups $(3.0 \%$ each). In these 2 individuals inhibited upbeat nystagmus was detected by only infrared eyeglasses. Significant differences in incidences of upbeat nystagmus were apparent between victims of DPAA exposure and both young and elderly control groups $(p<0.001)$, but no significant difference in incidence was seen between young and elderly control groups $(p>0.9)$. This suggests that age has little impact on the incidence of upbeat nystagmus.

DPAA-exposed subjects with upbeat nystagmus showed significantly higher DPAA concentrations in well water to which they were exposed and also significantly higher frequency of symptoms such as dizziness and floating, compared to those without upbeat nystagmus $(\mathrm{p}<0.01)$ (Table 2).

The slow-phase amplitude of upbeat nystagmus increased with increasing DPAA concentrations in nails (Fig. 2A). A significant positive correlation existed between these two parameters $(r=0.54, p<$ 0.05). The frequency of upbeat nystagmus also decreased with increasing DPAA concentrations in nails (Fig. 2B), and a significant negative correlation existed between these two parameters $(r=0.57, p<$ $0.05)$.

No correlation was seen between eye movement parameters such as the speed of the slow phase, or the amplitude or speed of the fast phase, and DPAA concentration in nails $(p>0.05)$. 


\section{2 SWJ}

SWJ were seen with high frequency in 13 of the 29 (45.0\%) exposed individuals (Fig 2). Mean frequency of SWJ was $112.4 \pm 16.7 / \mathrm{min}$ (range, 30.6-208.8/min).

SWJ frequency $\geq 30 /$ min was not seen in the young healthy group and was seen in only 1 person (3.0\%) in the elderly healthy group, at $48 / \mathrm{min}$. Significant differences in SWJ frequency were seen between the DPAA exposure group and both the young and elderly healthy groups ( $<<0.01$ each). A significant difference was also seen between the young and elderly healthy groups $(\mathrm{p}<0.03)$.

\section{DISCUSSION}

Our results show that non-rotational dizziness, lightheadedness, and shaking persisted in a significant number of exposure victims even during the chronic phase, several years after last exposure, and that a high frequency of abnormal eye movements remained.

Much remains unclear concerning the pharmacokinetics of DPAA, and estimating the total amount of internal exposure to DPAA in exposed victims is extremely difficult. Almost all DPAA is excreted in the urine and faeces after ingestion, with some being transferred to tissues (Kobayashi et al., 2008; Naranmandura et al., 2009). DPAA tends to be difficult to detect in serum even during exposure. As this chemical concentrates in the nails after being transferred from blood to tissue, DPAA concentrations in nails reflect accumulation. We therefore considered that DPAA concentrations in nails measured at the time of discovery reflect the level of DPAA exposure.

\section{1 Cytotoxicity of DPAA}

Experimental oral administration of DPAA to rats and monkeys has shown that this chemical tends to be transferred to and accumulate in the brain (Kato et al., 2007; Ishii et al., 2007; Kobayashi et al., 2008; Naranmandura et al., 2009). In particular, experiments on monkeys have confirmed preferential accumulation in the brainstem and cerebellum. DPAA has also been shown to have cytotoxic properties, binding to thiol (SH) groups within cells and damaging cellular metabolism (Kato et al., 2007; Kita et al., 2007). Experiments on human hepatoma cell lines have also shown that DPAA forms a conjugate with glutathione, increasing toxicity by around 1000-fold, and selectively inhibiting glutaminase (Ochi et al., 
2004; Hayakawa et al., 2005; Ochi et al., 2006; Kinoshita et al., 2006). Glutaminase is an important enzyme involved in the supply of glutamic acid, a major excitatory neurotransmitter in the mammalian CNS. Glutaminase inhibition by DPAA may thus be involved in the mechanisms of damage in the CNS.

\subsection{Pathogenesis of upbeat nystagmus}

The present results showed that upbeat nystagmus may be the cause of subjective symptoms and a neurological manifestation caused by DPAA intake. The present results also suggest that increased DPAA concentration in nails, indicating increased exposure to DPAA, affects the properties of upbeat nystagmus via CNS damage.

Peripheral vestibular disorder has been reported with arsenic exposure in an animal experiment (Vignaux et al., 2012), but peripheral vestibular disorder appears an unlikely cause of nystagmus among DPAA-exposed individuals given that the neurological symptoms were not associated with any disorder of the cochlear or vestibular nerves.

Experimental oral administration of DPAA to mice has mainly shown damage to the cerebellum, particularly Purkinje cells, rather than the cerebrum (Kato et al., 2007). However, direct damage to Purkinje cells in the cerebellar flocculus, which plays an important role in the onset of nystagmus, normally results in the appearance of downbeat nystagmus (Zee et al., 1981; Sato and Kawasaki 1990). In terms of the mechanisms involved, animal experiments and clinical trials have shown that the cerebellar flocculus only regulates the secondary vestibular neurons that receive input from the anterior semicircular canal in an inhibitory fashion, and does not project to the remaining secondary vestibular neurons that receive input from the posterior semicircular canal (Zee et al., 1981; Sato and Kawasaki 1990). The occurrence of upbeat nystagmus in exposure victims indicates that DPAA-induced CNS damage is not restricted to the cerebellum alone. Reports of single photon emission computed tomography (SPECT) brain blood flow imaging and brain positron emission tomography (PET) in DPAA exposure victims during the chronic phase have also strongly suggested damage to the brainstem rather than to the cerebellum alone (Ishii et al., 2007; Nakamagoe 2012).

Upbeat nystagmus can occur when vestibular balance impairment is elicited by inactivation of the ventral tegmental tract (VTT), which runs from the vestibular nucleus to the oculomotor neurons via the pons (Pierrot-Deseilligny and Milea 2005). 
The VTT pathway, which consists of bundles of nerve fibres, may also be directly damaged by DPAA to produce upbeat nystagmus. However, this mechanism appears unlikely from the perspective of the cytotoxic properties of DPAA (Kato et al., 2007; Kita et al., 2007).

However, another important mechanism also induces upbeat nystagmus. This mechanism consists of damage to the medullary neurons that project to the cerebellar flocculus, indirectly inactivating the VTT pathway (Pierrot-Deseilligny and Milea 2005). As DPAA accumulates in the brainstem and induces cytotoxicity, upbeat nystagmus may also appear as a result of damage to these medullary neurons (Fig. 3). These neurological mechanisms suggest that upbeat nystagmus may reflect damage to the brainstem, rather than to the cerebellum.

\subsection{Association between properties of upbeat nystagmus and DPAA concentration}

The upward gaze-evoked nystagmus observed in this study is known to appear as a result of damage to the eye position retention mechanism (neural integrator) of the brainstem and cerebellum, and is of high diagnostic value for identifying damaged locations. In particular, the interstitial nucleus of Cajal, the vestibular nucleus, paramedian tract neurons, and the cerebellar flocculus are sites known to house vertical neural integrators (Cannon and Robinson 1987; Fukushima et al., 1992; Büttner-Ennever and Horn 1996; Nakamagoe et al., 2000). If these neural integrators are damaged, the slow phase of nystagmus typically exhibits a pattern that varies exponentially rather than in a linear pattern. A slow phase with an exponential time course usually reflects the severity of injury to those neural integrators.

From our findings in this study, a conceivable hypothesis for residual CNS damage due to DPAA is that long-term exposure to DPAA causes accumulation in the CNS, resulting in cytotoxic nerve damage in the medulla oblongata. This would progressively affect neurons associated with neural integrators adjacent to the brainstem other than the medulla oblongata. The toxicity of DPAA thus affects the properties of the slow phase of nystagmus via damage to the neural integrators. We found a positive correlation between DPAA concentration in nails and amplitude of the slow phase. In addition, increased amplitude and time of the slow phase in upbeat nystagmus reduces the frequency of nystagmus, explaining the negative correlation with DPAA levels.

\subsection{SWJ}


SWJ seen clinically were classified as square oscillations among abnormal eye movements. However, it is known from past reports that low-frequency SWJ are also seen in healthy people (Herishanu and Sharpe, 1981; Salman et al., 2006). SWJ are also affected by aging, and their frequency is important in judging whether they are pathological. Pathological significance is thought to be higher with greater frequency. In past reports, the mean SWJ frequency in healthy people was $3 /$ min in a young group with a mean age of 13.8 years, $4.7 / \mathrm{min}$ in a group with a mean age of 32 years, and $27 / \mathrm{min}$ in an elderly group with a mean age of 71 years (Herishanu and Sharpe, 1981; Salman et al., 2006). Based on these reports, analysis in the present study was performed taking SWJ with frequency $\geq 30 /$ min as pathological. In this study, SWJ were seen in only 1 person in the healthy elderly group, which had a mean age of 71 years. The present results showed that the occurrence of SWJ is affected by age, but the high frequency in the DPAA exposure group is not within the normal physiological range. In particular, a SWJ frequency $\geq 30 /$ min appears highly likely to be pathologically significant.

SWJ have been reported to occur in association with central nerve disorders in the cerebellum, brainstem, and cerebrum (Jones et al., 1983; Rascol et al., 1991). In addition, with regard to SWJ frequency, Sharpe et al. reported that compared with the SWJ frequency of $43 \pm 24 / \mathrm{min}$ that occurs in cerebellar diseases, the frequency of SWJ originating from cerebral disorders is lower, at $27 \pm 17 / \mathrm{min}$ (Sharpe et al. 1982). SWJ in the DPAA exposure group appear to reflect central nervous system disorder.

\section{Conclusion}

Our findings suggest that ocular movement disorders during the chronic phase are affected by the level of organoarsenic exposure. Abnormal eye movements may thus potentially provide an indicator for screening for CNS toxicity due to poisoning such as organoarsenic exposure. In combination with imaging tests such as PET, these findings may provide an effective means of evaluating chronic-phase brain damage due to poisoning. 


\section{FUNDING}

This work was supported by research conducted by the Japanese Ministry of the Environment: DIFENIRUARUSINSANTOU NO KENKO-EIKYO NI KANSURUCYOSA-KENKYU (Research on the influence of diphenylarsinic acid and related compounds on human health) and a Grant for Scientific Research (C) (No. 23590869) from the Ministry of Education, Culture, Sports, Science, and Technology of Japan.

\section{DISCLOSURE}

The authors report no conflicts of interest. 


\section{REFERENCES}

Büttner-Ennever JA, Horn AK. Pathways from cell groups of the paramedian tracts to the floccular region. Ann N Y Acad Sci 1996;781:532-40.

Cannon SC, Robinson DA. Loss of the neural integrator of the oculomotor system from brain stem lesions in monkey. J Neurophysiol 1987;57:1383-409.

Fukushima K, Kaneko CR, Fuchs AF. The neuronal substrate of integration in the oculomotor system. Prog Neurobiol 1992;39: 609-39.

Hayakawa T, Kobayashi Y, Cui X, Hirano S. A new metabolic pathway of arsenite: arsenic-glutathione complexes are substrates for human arsenic methyltransferase Cyt19. Arch Toxicol 2005;79: 183-91.

Herishanu YO, Sharpe JA. Normal square wave jerks. Invest Ophthalmol Vis Sci 1981;20: 268-72.

Ishii K, Tamaoka A, Otsuka F, Iwasaki N, Shin K, Matsui A, et al. Diphenylarsinic acid poisoning from chemical weapons in Kamisu, Japan. Ann Neurol 2004;56: 741-5.

Ishii K, Shibata Y, Hosoya T, Takeda T, Iwasaki N, Nakamagoe K, et al. Central nervous effect of organoarsenic compound: clinical and neurological features of diphenylarsinic acid (DPAA) intoxication, in Kamisu, Japan. In: Morita M (ed) Persistent Organic Pollutants (POPs) Research in Asia. DIOXIN2007 International symposium organizing committee: Tokyo: pp 387-392; 2007.

Ishizaki M, Yanaoka T, Nakamura M, Hakuta $\mathrm{T}$, Ueno $\mathrm{S}$, Komuro $\mathrm{M}$, et al. Detection of bis(diphenylarsine)oxide, diphenylarsinic acid and phenylarsenic acid, compounds probably derived from chemical warfare agents, in drinking well water. Journal of Health Science 2005;51: 130-7.

Jones A, Friedland RP, Koss B, Stark L. Thompkins-Ober BA. Saccadic intrusions in Alzheimer-type dementia. J Neurol 1983;229: 189-94.

Kato K, Mizoi M, An Y, Nakano M, Wanibuchi H, Endo G, et al. Oral administration of diphenylarsinic acid, a degradation product of chemical warfare agents, induces oxidative and nitrosative stress in cerebellar Purkinje cells. Life Sci 2007;81: 1518-25.

Kawasaki S, Yazawa S, Ohnishi A, Ohi T. Chronic and predominantly sensory polyneuropathy in Toroku Valley where a mining company produced arsenic. Rinsho Shinkeigaku 2002;42: 504-11.

Kobayashi Y, Negishi T, Mizumura A, Watanabe T, Hirano S. Distribution and excretion of arsenic in cynomolgus monkey following repeated administration of diphenylarsinic acid. Arch Toxicol 2008;82: 553-61. 
Kinoshita K, Ochi T, Suzuki T, Kita K, Kaise T. The role of glutathione on the cytotoxic effects and cellular uptake of diphenylarsinic acid, a degradation product of chemical warfare agents. Arch Toxicol 2006;80: 486-91.

Kinoshita K, Ochi T, Suzuki T, Kita K, Kaise T. Glutathione plays a role in regulating the formation of toxic reactive intermediates from diphenylarsinic acid. Toxicology 2006;225: 142-9.

Kinoshita K, Noguchi A, Ishii K, Tamaoka A, Ochi T, Kaise T. Urine analysis of patients exposed to phenylarsenic compounds via accidental pollution. J Chromatogr B 2008;867: 179-88.

Kita K, Suzuki T, Ochi T. Down-regulation of glutaminase C in human hepatocarcinoma cell by diphenylarsinic acid, a degradation product of chemical warfare agents. Toxicol Appl Pharmacol 2007;220: 262-70.

Leigh RJ, Zee DS. The neurology of eye movements. 4th ed. New York: Oxford University press; 2006.

Nakamagoe K, Iwamoto Y, Yoshida K. Evidence for brainstem structures participating in oculomotor integration. Science 2000;288: 857-9.

Nakamagoe K, Ishii K, Tamaoka A, Shoji S. Upward gaze-evoked nystagmus with organoarsenic poisoning. Neurology 2006;66: 131-2.

Nakamagoe K. Abnormalities in vertical eye movements in patients with organic arsenic poisoning. Neuro-ophthal Jpn 2012;29: 42-52.

Naranmandura H, Suzuki N, Takano J, McKnight-Whitford T, Ogra Y, Suzuki KT, et al. Systemic distribution and speciation of diphenylarsinic acid fed to rats. Toxicol Appl Pharmacol 2009;237: 214-20.

Ochi T, Suzuki T, Isono H, Kaise T. In vitro cytotoxic and genotoxic effects of diphenylarsinic acid, a degradation product of chemical warfare agents. Toxicol Appl Pharmacol 2004;200: 64-72.

Pierrot-Deseilligny C, Milea D. Vertical nystagmus: clinical facts and hypotheses. Brain 2005;128: $1237-46$.

Rascol O, Sabatini U, Simonetta-Moreau M, Montastruc JL, Rascol A, Clanet M. Square wave jerks in parkinsonian syndromes. J Neurol Neurosurg Psychiatry 1991;54: 599-602.

Salman MS, Sharpe JA, Eizenman M, Lillakas L, To T, Westall C, et al. Saccadic adaptation in children. J Child Neurol 2006;21: 1025-31.

Sato Y, Kawasaki T. Operational unit responsible for plane-specific control of eye movement by cerebellar flocculus in cat. J Neurophysiol 1990;64: 551-64. 
Sharpe JA, Herishanu YO, White OB. Cerebral square wave jerks. Neurology 1982;32: 57-62.

Vignaux G, Chabbert C, Gaboyard-Niay S, Travo C, Machado ML, Denise P, et al. Evaluation of the chemical model of vestibular lesions induced by arsanilate in rats. Toxicol Appl Pharmacol 2012;258: $61-71$.

Zee DS, Yamazaki A, Butler PH, Gücer G. Effects of ablation of flocculus and paraflocculus on eye movements in primate. J Neurophysiol 1981;46: 878-99. 


\section{FIGURE LEGENDS}

Figure 1. Electronystagmographic findings in the vertical eye movements

A) A case of typical upbeat nystagmus seen in a DPAA-exposed patient.

The patient was a 47-year-old woman. This test was performed 2272 days after she last drank the contaminated water. The record shows dark-field, non-gaze eye movements. The top line shows vertical eye movements, and the bottom line shows velocity waveforms.

B) A normal subject (A 61-year-old female)

No nystagmus was observed in this case.

Figure 2. Electronystagmographic findings in the horizontal eye movements

A) A case of typical square-wave jerks $(\mathrm{SWJ})$ seen in a DPAA-exposed patient. The patient was a 51-year-old man. This shows a horizontal electronystagmogram (DC recording) in a bright field performed 1,461 days after he last drank the DPAA-contaminated water. The upper waveform shows the horizontal eye position and the lower waveform shows movement velocity of that eye.

B) A normal subject (A 61-year-old female)

No SMJ was observed in this case.

Figure 3. Relationship between DPAA concentration and properties of upbeat nystagmus

A) Slow-phase amplitude of upbeat nystagmus increased with increasing DPAA concentration in nails. A significant positive correlation existed between these parameters $(r=0.54, p=0.04)$.

B) The frequency of upbeat nystagmus decreased with increasing DPAA concentration in nails. A significant negative correlation existed between these parameters $(r=0.57, p=0.03)$.

Figure 4. Possible pathogenesis of upbeat nystagmus due to organoarsenic poisoning.

This figure illustrates nerve pathways for vertical eye movements.

If neurons projecting into the cerebellar flocculus, located in the medulla oblongata, are damaged by DPAA, inhibition of the cerebellum is decreased. This results in increased activity of floccular Purkinje cells, in turn increasing inhibition of the secondary vestibular neurons that receive inputs from the anterior semicircular canals. As a result, activity of the corresponding antagonistic oculomotor neurons is 
respectively inhibited and stimulated. This causes a downward eye movement that forms the slow phase of nystagmus. Upward eye movement (fast phase) then appears to compensate for this slow downward phase, generating upbeat nystagmus.

P, Purkinje cells; G, granulocytes; PMT neurons, paramedian tract neurons. White circles indicate excitatory neurons, and black circles indicate inhibitory neurons. 
Fig. 1

A

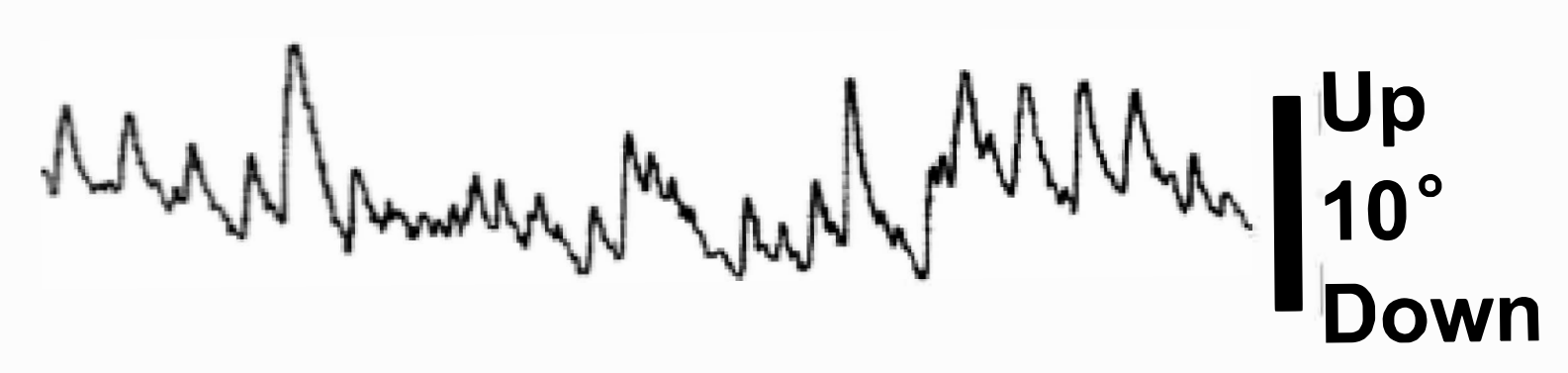

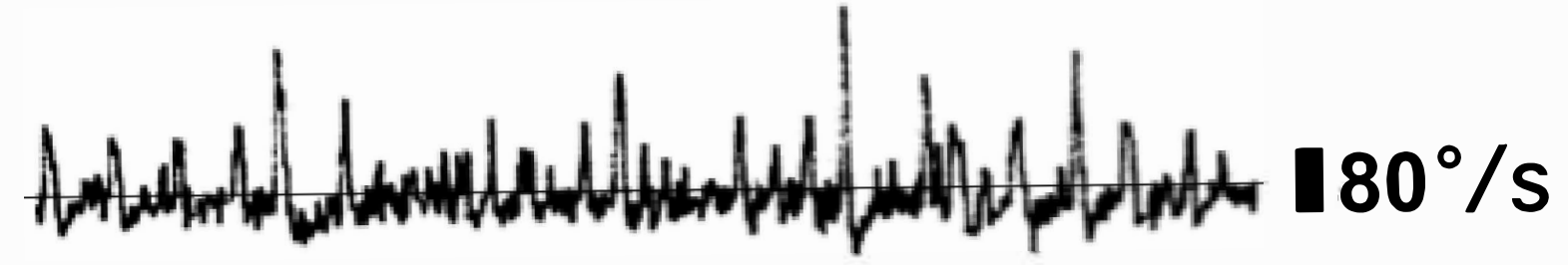

$4 \mathrm{~s}$

B

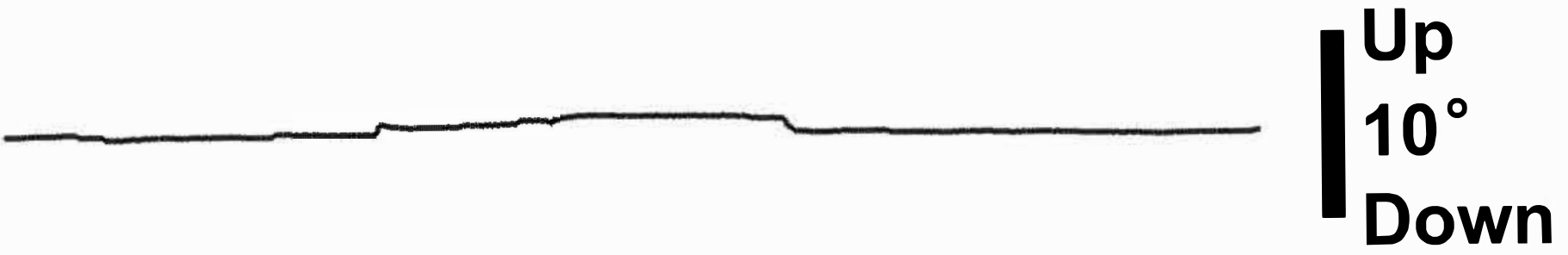

l

$180 \% \mathrm{~s}$ 
Fig. 2

A

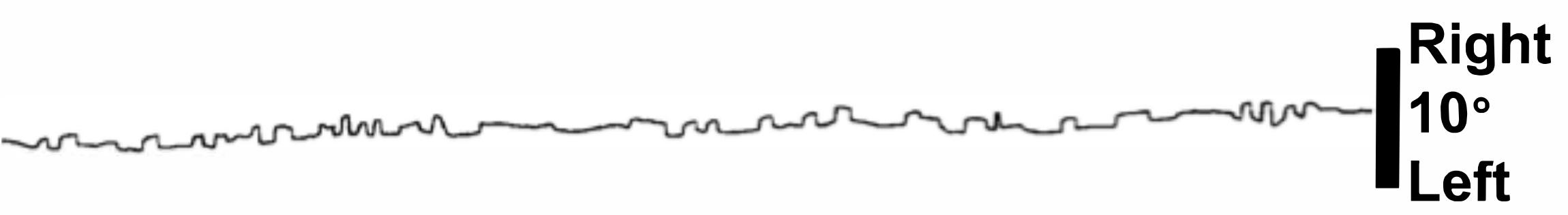

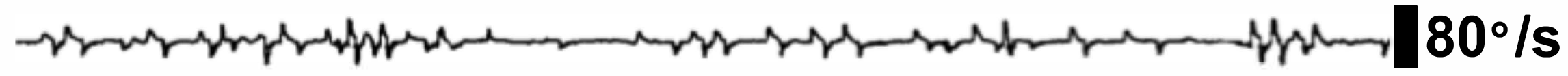

\section{$2 \mathrm{~s}$}

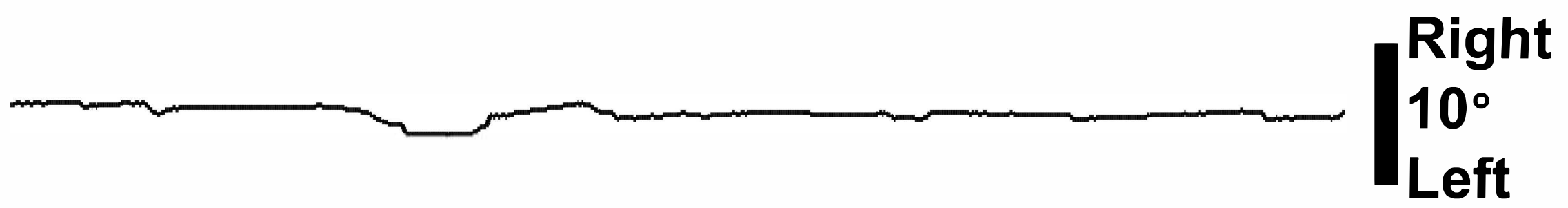

180\% 
Table 1. Characteristics of individuals exposed to diphenylarsinic acid (DPAA)

\begin{tabular}{|l|c|c|c|}
\hline & DPAA exposure (n=29) & Young control (n=32) & Elderly control (n=32) \\
\hline \hline Age, years (mean \pm SD, range) & $44.0 \pm 15.3(14-67)$ & $22.5 \pm 0.2(18-26)$ & $70.6 \pm 0.4(64-80)$ \\
\hline Males/females & $15 / 14$ & $16 / 16$ & $16 / 16$ \\
\hline Symptom; dizziness and floating (n,\%) & $11(38 \%)$ & $0(0 \%)$ & $0(0 \%)$ \\
\hline Nystagmus; Upbeat nystagmus & $23(79 \%)$ & $1(3 \%)^{\mathrm{a}}$ & $1(3 \%)^{\mathrm{a}}$ \\
detected by ENG (n,\%) & $15(52 \%)$ & $0(0 \%)$ & $0(0 \%)$ \\
detected only with infrared eyeglasses (n,\%) & $8(28 \%)$ & $1(3 \%)$ & $1(3 \%)$ \\
Upward gaze-evoked nystagmus (n,\%) & $7(24 \%)$ & $0(0 \%)$ & $0(0 \%)$ \\
Horizontal gaze-evoked nystagmus (n,\%) & $6(21 \%)$ & $0(0 \%)$ & $0(0 \%)$ \\
\hline Square-wave jerks (SWJ) (n,\%) & $13(45 \%)$ & $0(0 \%)$ & $1(3 \%)$ \\
\hline
\end{tabular}

${ }^{a}$ A significant difference was apparent between victims of DPAA exposure and both young and elderly control groups $(p<0.01)$ 
Table 2. Characteristics of individuals exposed to diphenylarsinic acid (DPAA) with or without upbeat nystagmus ( $\mathrm{n}=29)$

\begin{tabular}{|l|c|c|c|}
\hline & DPAA exposure (n=29) & DPAA exposure with upbeat nystagmus (n=23) & DPAA exposure without upbeat nystagmus (n=6) \\
\hline \hline Age, years (mean \pm SD, range) & $44.0 \pm 15.3(14-67)$ & $42.6 \pm 16.6(14-67)$ & $49.7 \pm 6.8(37-56)^{\text {a }}$ \\
\hline Males/females & $15 / 14$ & $11 / 12$ & $4 / 2$ \\
\hline Symptom; dizziness and floating (n, \%) & $11(38 \%)$ & $11(48 \%)$ & $0(0 \%)^{\mathrm{b}}$ \\
\hline $\begin{array}{l}\text { Mean duration of drinking DPAA-contaminated water } \\
(m e a n \pm \text { SD) }\end{array}$ & $1420 \pm 389$ days & $1351 \pm 310$ days & $1687 \pm 562$ days ${ }^{\text {a }}$ \\
\hline $\begin{array}{l}\text { Mean duration after last drinking DPAA-contaminated } \\
\text { water before ENG (mean } \pm \text { SD) }\end{array}$ & $1452 \pm 505$ days & $1551 \pm 461$ days & $1073 \pm 527$ days \\
\hline Mean DPAA concentration in well water (mean \pm SD) & $628.4 \pm 945.1 \mathrm{ngAs} / \mathrm{ml}$ & $762.4 \pm 1019.8 \mathrm{ngAs} / \mathrm{ml}$ & $114.4 \pm 159.7 \mathrm{ngAs} / \mathrm{ml}{ }^{\mathrm{b}}$ \\
\hline Mean maximum DPAA concentration in nails (mean $\pm \mathrm{SD})$ & $841.0 \pm 1763.6 \mathrm{ng} / \mathrm{g}$ & $1020.9 \pm 1945.0 \mathrm{ng} / \mathrm{g}$ & $152.7 \pm 235.5 \mathrm{ng} / \mathrm{g}$ \\
\hline
\end{tabular}

${ }^{a}$ A significant difference was apparent between victims of DPAA exposure with upbeat nystagmus and without upbeat nystagmus $(p<0.05)$

${ }^{\mathrm{b}}$ A significant difference was apparent between victims of DPAA exposure with upbeat nystagmus and without upbeat nystagmus $(p<0.01)$ 